\title{
Dietary Diversity Is Not Associated with Haematological Status of Pregnant Women Resident in Rural Areas of Northern Ghana
}

\author{
Mahama Saaka, ${ }^{1}$ Jeremiah Oladele, ${ }^{1}$ Asamoah Larbi, ${ }^{2}$ and Irmgard Hoeschle-Zeledon ${ }^{3}$ \\ ${ }^{1}$ School of Allied Health Sciences, University for Development Studies, P.O. Box 1883, Tamale, Ghana \\ ${ }^{2}$ International Institute of Tropical Agriculture (IITA), P.O. Box 6, Tamale, Ghana \\ ${ }^{3}$ International Institute of Tropical Agriculture (IITA), Oyo Road, PMB 5320, Ibadan, Nigeria
}

Correspondence should be addressed to Mahama Saaka; mmsaaka@gmail.com

Received 30 August 2016; Revised 20 November 2016; Accepted 18 December 2016; Published 11 January 2017

Academic Editor: A. Venketeshwer Rao

Copyright (C) 2017 Mahama Saaka et al. This is an open access article distributed under the Creative Commons Attribution License, which permits unrestricted use, distribution, and reproduction in any medium, provided the original work is properly cited.

\begin{abstract}
Background. Information regarding how dietary diversity is related to haematological status of the pregnant women in rural areas of Northern Ghana is limited. This study therefore evaluated maternal dietary intake and how it relates to the nutritional status of pregnant women belonging to different socioeconomic conditions in Northern Ghana. Methods. This study was cross-sectional in design involving 400 pregnant women. Midupper arm circumference (MUAC) and anaemia status were used to assess the nutritional status of pregnant women. Results. The mean dietary diversity score (DDS) of the study population from ten food groups was $4.2 \pm 1.5$ (95\% CI: 4.08 to 4.37 ). Of the 400 women, $46.1 \%$ (95\% CI: 40.0 to 52.2 ) met the new minimum dietary diversity for women (MDD-W). The mean haemoglobin concentration among the pregnant women studied was $10.1 \mathrm{~g} / \mathrm{dl} \pm 1.40$ ( $95 \%$ CI: 9.8 to 10.3 ). The independent predictors of haemoglobin concentration were maternal educational attainment, gestational age, frequency of antenatal care (ANC) attendance, number of under-five children in the household, size of MUAC, and maternal height. Conclusions. Irrespective of the socioeconomic status, women minimum dietary diversity (MDD-W) was not associated with anaemia among pregnant women resident in the rural areas of Northern Ghana.
\end{abstract}

\section{Introduction}

Pregnant women in developing countries including Ghana enter gestation with depleted or low body iron stores which might make them prone to developing iron deficiency anaemia (IDA) [1]. Such women are most vulnerable because of the increased metabolic demands including a growing placenta, foetus, and maternal tissues, coupled with poor diets [2]. This vulnerability often leads to adverse effects such as premature delivery, intrauterine growth retardation, increased risk of malnutrition, mortality, and morbidity on both mother and growing foetus [1,3-5]. During pregnancy, dietary energy and nutrient requirements are generally increased to support increased maternal metabolism, blood volume, and red cell mass expansion, and the delivery of nutrients to the foetus.

Several studies have shown a lack of diversity among poor populations, whose diets are predominantly carbohydrates with little or no animal products, fruits, and vegetables $[2,5]$.
Multicountry studies have provided empirical evidence that dietary diversity scores are reliable measures for micro- and macronutrient adequacy for women of reproductive ages [6]. So a diverse diet of a pregnant woman is expected to improve her nutritional profile and thus reduce the risk of maternal and child mortality and morbidity. If the diet lacks diversity, it will be deficient in essential nutrients such as iron which is required for blood formation.

It is well documented that adequate nutritional status of women especially during pregnancy is crucial for child survival because an undernourished mother is more likely to deliver an infant with low birth weight, significantly increasing its risk of dying [7-12]. A pregnant woman whose diet lacks diversity is most likely to be deficient in essential nutrients, thereby depriving the foetus of the nutrition it requires to have a healthy growth [13-15].

Though dietary diversity is a recognized indicator of diet quality, there is limited knowledge on how it affects the nutrition status of pregnant women in rural areas of Northern 
Ghana. This study therefore sought to assess dietary diversity and how it relates to the nutritional status of pregnant women belonging to different socioeconomic conditions in Northern Ghana.

\section{Methods}

2.1. Study Area. The study covered 25 communities located in five districts of Northern Ghana. The International Institute of Tropical Agriculture (IITA) is currently operating in these districts, namely, Nadowli, Wa West in the Upper West Region (UWR), Tolon and Savelugu in the Northern Region (NR), and Kassena-Nankana in the Upper East Region (UER).

The study area is characterized by high poverty and recurrent droughts and floods which predispose communities to increased vulnerability to food insecurity and malnutrition. The Ghana Living Standards Survey Round 6 Report showed that the three study regions have high proportions of households in the lowest quintile than in the highest quintile. The UWR has the highest proportion of households in the lowest quintile (55.7\%) and the NR recorded the lowest proportion in the highest quintile (10.2\%) [16]. These are indication that poverty is more prevalent in the three northern regions, particularly in the Upper West Region.

The three regions share some boundaries with each other. The UER shares its northern boundary with Burkina Faso and its eastern boundary with the Republic of Togo. The UWR on the other hand has a northern boundary with Burkina Faso and a western boundary with La Cote d'Ivoire. The UER and UWR share their southern boundaries with the NR which also has La Cote d'Ivoire to the west and Togo to the east.

The majority of the people have agriculture as their main occupation whilst some are involved in trading. The main staple foods including maize, sorghum, millet, and yam are usually harvested from October through December. Although the food security situation is usually good during the harvesting time, child care tends to suffer because of lack of time on the part of rural mothers. A high proportion of rural women work daily away from home and therefore frequently face challenges to the care of children.

The rainfall pattern is unimodal and the period is usually short and lasts from May to August, followed by a long dry season (September-April) with dry harmattan winds.

2.2. Study Design, Population, and Sampling. This study was an analytical cross-sectional survey involving 400 pregnant women in different stages of gestation, conducted in 5 districts of Northern Ghana. All the IITA five communities in each district were included in the study. All women independent of their stage of pregnancy were asked to participate in the study if they met the inclusion criteria. The inclusion criteria were being pregnant but not seriously ill. Also, pregnant women who could not hear and/or speak were excluded from the study.

The basic primary sampling unit was the household in which there was a pregnant woman. With the assistance of community health volunteers, a complete list of all households was compiled and were serially numbered in each community. Systematic random sampling was then used in selecting study households. To get the sampling interval, the total number of households in a cluster was divided by the cluster size of 16 . The first household was randomly selected by picking any number within the sample interval. Subsequent selections were made by adding the sampling interval to the selected number in order to locate the next household to visit. If the selected household does not have a target respondent, then next household was selected using the systematic sampling procedure.

The sample size was determined on the assumption that $50 \%$ of the pregnant mothers are anaemic with 5\% marginal error and 95\% confidence interval (CI) and a nonresponse rate of $5 \%$. Based on this assumption, the actual sample size for the study was determined using the formula for one-point sample estimation:

$$
n=\frac{t^{2} \times p(1-p)}{m^{2}}
$$

where $n$ is the required sample size, $t$ is the confidence level at $95 \%$ (standard value of 1.96), $p$ is the estimated prevalence of anaemia in the domain area (50.0\%), and $m$ is the margin of error at $5 \%$ (standard value of 0.05 ). This yielded a minimum sample size of 400 .

2.3. Data Collection. Information was obtained through a face-to-face interview with mothers in their homes. The primary dependent variable was anaemia status of pregnant women. The main independent explanatory variable was dietary quality as measured by individual dietary diversity scores. The covariate variables included gestational age, marital status, maternal age, height, educational level, occupation, religion, household wealth, number of under-fives in household, parity, birth interval, antenatal care (ANC) during current pregnancy, and midupper arm circumference (MUAC).

2.4. Assessment of Dietary Diversity. Overall dietary quality was assessed using the individual dietary diversity since it has been shown to indicate adequate nutrient intake $[5,17]$ and can be used as a proxy indicator for measuring nutrient adequacy among pregnant females [1]. Dietary assessment was made through administration of the 24-hour foodfrequency questionnaire (FFQ).

Women's dietary diversity scores (WDDSs) which are based on a 24-hour dietary recall period and the number of food groups consumed [18] were applied to characterize the average usual dietary intake of pregnant women in the study area. The food groups used were all starchy staple foods, beans, peas, nuts, seeds, dairy, flesh foods, eggs, vitamin A-rich dark green leafy vegetables, other vitamin A-rich vegetables and fruits, other vegetables, and other fruits.

Women having a diversity score of less than 5 were classified as having low dietary diversity and scores of 5-10 were classified in the high dietary diversity scores.

2.5. Nutritional Status Assessment. Midupper arm circumference (MUAC) and haemoglobin levels were used to assess the 
nutritional status of the pregnant women. MUAC was used as a proxy for body weight, since it is not affected by gestational age [19]. MUAC was measured to the nearest $0.1 \mathrm{~cm}$, and values below $25.0 \mathrm{~cm}$ were classified in the analyses as an indicator of low body weight.

There is currently no internationally agreed MUAC cutoffs. A recent multicountry study concluded that it may be difficult to recommend a MUAC cutoff that would be suitably discriminatory in all settings [20].

2.6. Haemoglobin Level Determination. Haemoglobin levels were determined by using a portable HemoCue 301 photometer. Trained laboratory technicians drew capillary blood samples from the finger prick with a lancet after taking all aseptic precautions. The first drop of blood was wiped away using alcohol sterile wipes, and the next drop was placed into the HemoCue curvette for immediate testing of haemoglobin.

According to WHO, anaemia is defined as presence of haemoglobin level of less than $11 \mathrm{~g} / \mathrm{dL}$ in pregnant women [21]. Anaemia was further classified as mild $(9.0-10.9 \mathrm{~g} / \mathrm{dL})$, moderate $(7.0-8.9 \mathrm{~g} / \mathrm{dL})$, or severe $(<7.0 \mathrm{~g} / \mathrm{dL})$. Anaemia is said to be a severe public health problem when its prevalence is $40 \%$ or more in any group (all types of anaemia) or when severe anaemia (haemoglobin $<7 \mathrm{~g} / \mathrm{dL}$ ) exceeds $2 \%$ [22].

2.7. Determination of Household Economic Status. A household wealth index based on household assets and housing quality was used as a proxy indicator for socioeconomic status (SES) of households. Principal Component Analysis (PCA) was used to determine household wealth index from information collected on housing quality (floor, walls, and roof material), source of drinking water, type of toilet facility, the presence of electricity, type of cooking fuel, and ownership of modern household durable goods and livestock (e.g., bicycle, television, radio, motorcycle, sewing machine, telephone, cars, refrigerator, mattress, bed, computer, and mobile phone) [23-26].

These facilities or durable goods are often regarded as modern goods that have been shown to reflect household wealth. A household of zero index score, for example, means that household had not a single modern good. The scores were thus added up to give the proxy household wealth index. The median of the total score was the cutoff point used to define low and high household wealth index.

2.8. Data Processing and Analysis. Data were analyzed using SPSS version 20 statistical software. Analysis of variance (ANOVA) was used to compare group mean differences. Association between anaemia and some risk factors in pregnancy was tested using chi-square and multivariable analysis of risk factors. Variables with $p$ value less than 0.1 in bivariate analysis were entered to multivariable linear regression model. Differences and associations were considered statistically significant at $p<0.05$. Multicollinearity was investigated by using the variance inflation factor (VIF). A VIF (the reciprocal of the tolerance statistics) of greater than 5 is generally considered evidence of multicollinearity.
2.9. Ethical Considerations. The School of Allied Health Sciences, University for Development Studies, approved the study protocol. Ethical clearance was obtained from the Institutional Review Board (IRB) of the Tamale Teaching Hospital (Ref number TTH/10/11/15/01). Participation in the study was voluntary and no incentives were provided.

\section{Results}

3.1. Sociodemographic Characteristics of the Sample. A total of 400 pregnant women were approached and all of them consented and accepted to participate in the study, thus giving a response rate of $100 \%$. The mean age of mothers was $26.2 \pm$ 6.4 years which range from 15 to 48 years. Majority $(54.0 \%)$ of the respondents were Muslims. Majority (85.5\%) of the respondents were married and (51.8\%) of the mothers had no formal education at all. Farming and petty trading were common among the mothers (Table 1).

3.2. Maternal Dietary Diversity during Pregnancy. The mean dietary diversity score (DDS) of study population from ten food groups was $4.2 \pm 1.5$ (95\% CI: 4.08 to 4.37 ). Of the 400 women, $46.1 \%$ (95\% CI: 40.0 to 52.2$)$ met the MDD-W.

3.3. Nutritional and Anaemia Status of Pregnant Women. Based on MUAC cutoffs, the overall prevalence of underweight (MUAC $<25.0 \mathrm{~cm}$ ) was $28.8 \%$ (95\% CI: 24.6 to 33.4 ), whilst $71.2 \%$ of the respondents were classified as normal (MUAC $\geq 25.0 \mathrm{~cm}$ ).

The mean haemoglobin concentration among the pregnant women studied was $10.1 \mathrm{~g} / \mathrm{dl} \pm 1.40$ (95\% CI: 9.8 to 10.3 ), and an overall prevalence of anaemia (haemoglobin level < $11 \mathrm{~g} / \mathrm{dl}$ ) was $70.0 \%$ (CI: 60.5 to 78.0 ). In terms of severity, mild anaemia was $46.8 \%$ (95\% CI: 37.9 to 56.0 ), moderate anaemia was $20.2 \%$ (CI: 15.8 to 25.5 ), and severe anaemia was $3.0 \%$ (CI: 1.4 to 6.0 ). The prevalence of anaemia was the highest in the Northern Region.

3.4. Analysis of Haemoglobin Levels Based on the Type of Food Groups Consumed among Pregnant Women. Analysis of haemoglobin cutoffs levels based on the type of foods consumed is shown in Table 2. Generally, consumption of food groups in the past 24 hours prior to the study was not associated with haemoglobin concentration levels.

3.5. Relationship between Women Minimum Dietary Diversity and Anaemia. The relationship between women minimum dietary diversity (MDD-W) and anaemia was investigated. Correlation analysis showed a positive association between household wealth index and dietary diversity score (DDS) $(r=0.2, p<0.001)$ but DDS was unrelated to Hb irrespective of the socioeconomic class. For the whole sample, DDS did not have an association with haemoglobin status of pregnant women $(r=-0.001, p=0.9)$. Similarly, the prevalence of anaemia was not different among women of low and high MDD-W (36.2 versus 33.8\%) $\left(\chi^{2}=1.9 ; p=0.17\right)$. This association existed, irrespective of the socioeconomic status. 
TABLE 1: Sample characteristics $(N=400)$.

\begin{tabular}{|c|c|c|}
\hline Variable & Frequency $(n)$ & Percentage (\%) \\
\hline \multicolumn{3}{|l|}{ Age groupings (years) } \\
\hline $15-24$ & 176 & 46.5 \\
\hline $25-34$ & 180 & 44.6 \\
\hline $35-49$ & 44 & 8.8 \\
\hline \multicolumn{3}{|l|}{ Religion } \\
\hline Christian & 176 & 44.0 \\
\hline Muslim & 216 & 54.0 \\
\hline Traditionalist & 8 & 2.0 \\
\hline \multicolumn{3}{|l|}{ Classification of occupation } \\
\hline Trader & 98 & 24.5 \\
\hline Farmer & 123 & 30.8 \\
\hline Civil servant & 2 & 0.5 \\
\hline Service worker & 67 & 16.8 \\
\hline Education/teacher & 5 & 1.3 \\
\hline Health worker & 3 & 0.8 \\
\hline Nothing & 102 & 25.5 \\
\hline \multicolumn{3}{|l|}{ Ethnicity } \\
\hline Dagomba & 119 & 29.8 \\
\hline Kassena & 71 & 17.8 \\
\hline Dagaba & 110 & 27.5 \\
\hline Kukomba & 2 & 0.5 \\
\hline Frafra & 14 & 3.5 \\
\hline Wala & 55 & 13.8 \\
\hline Fulani & 2 & 0.5 \\
\hline Dorimor & 27 & 6.8 \\
\hline \multicolumn{3}{|l|}{ Education level of mother } \\
\hline None & 207 & 51.8 \\
\hline Low (primary and junior high) & 157 & 39.3 \\
\hline High ( $\geq$ senior high) & 36 & 9.0 \\
\hline \multicolumn{3}{|l|}{ Marital status } \\
\hline Single & 8 & 2.0 \\
\hline Married & 342 & 85.5 \\
\hline Widowed & 5 & 1.3 \\
\hline Cohabiting & 33 & 8.3 \\
\hline Separated & 12 & 3.0 \\
\hline
\end{tabular}

3.6. Factors Associated with Anaemia. Bivariate analyses were performed to assess association of sociodemographic and other factors with anaemia (Table 3). The overall prevalence of anaemia fell with gestational age. Both educational level and household wealth index were negatively associated with anaemia. Pregnant women in the Upper West Region had a lower prevalence of anaemia than Northern and Upper East Regions. The bivariate analysis showed that pregnant women with a midupper arm circumference (MUAC) less than $25 \mathrm{~cm}$ were more likely to be anaemic, compared to MUAC $\geq 25.0 \mathrm{~cm}$ (79.0\% versus $58.9 \%)$.

A multiple linear regression analysis was performed to identify the predictors of haemoglobin concentration. Potential explanatory variables that were tested but found insignificant were dietary diversity, age of woman, and reported episodes of malarial infections. Region of residence correlated with a number of the explanatory variables and was therefore removed from the model.

The significant independent determinants of $\mathrm{Hb}$ were maternal educational attainment, gestational age, frequency of ANC attendance, number of under-five children in the household, size of MUAC, and maternal height. The set of independent variables could explain $11.3 \%$ of the variance in haemoglobin concentration (Adjusted $R$ Square $=0.113$ ).

Considering the beta coefficients $(\beta)$, women who attended ANC at least four times had mean $\mathrm{Hb}$ concentration which was 0.147 standardized units significantly higher than women who attended less than four times. There was an inverse relationship between the prevalence of anaemia and the level of education of the women. Mean $\mathrm{Hb}$ of women whose educational level was at least senior high school was significantly higher by 0.122 units. Women of higher MUAC had higher $\mathrm{Hb}$ (beta coefficient $=0.216, p<0.001$ ). On the average, a unit increase in gestational age was associated with reduced mean $\mathrm{Hb}$ of 0.172 standardized units. A $1 \mathrm{~cm}$ increase in maternal height was associated with an increase of 0.14 units in haemoglobin concentration $(\beta=0.141, p=0.006)$ (Table 4).

\section{Discussion}

The dietary intake of a woman during pregnancy is important because suboptimal diet negatively impacts the health of the mother, the foetus, and the newborn. This study therefore sought to assess maternal dietary intake and how this relates to the haematological status of pregnant women belonging to different socioeconomic conditions in Northern Ghana.

The risk factors of anaemia during pregnancy are multifactorial and the relative contribution of each of these factors varies greatly by geographical location, season, and dietary practice [27]. Whilst controlling for potential confounding factors in multivariable analysis, haematological status of pregnant women was not associated with maternal dietary diversity score (DDS). The significant independent determinants of $\mathrm{Hb}$ were maternal educational attainment, gestational age, frequency of ANC attendance, number of under-five children in the household, size of MUAC, and increased maternal height.

In bivariate analysis, some potential explanatory variables including household wealth index, self-reported episodes of malarial infection, and maternal age were tested but found insignificant.

4.1. Prevalence of Anaemia. The prevalence of anaemia among pregnant women was $70.0 \%$ and this can be classified as a severe public health problem according to WHO [22]. The prevalence is higher than the $51.9-59.6 \%$ estimated prevalence of anaemia in pregnancy in Africa [28]. The finding is also higher than that from the 2014 Ghana Demographic and Health Survey (GDHS) in which, overall, 44.6\% of pregnant women in Ghana suffered from some degree of anaemia [29]. 


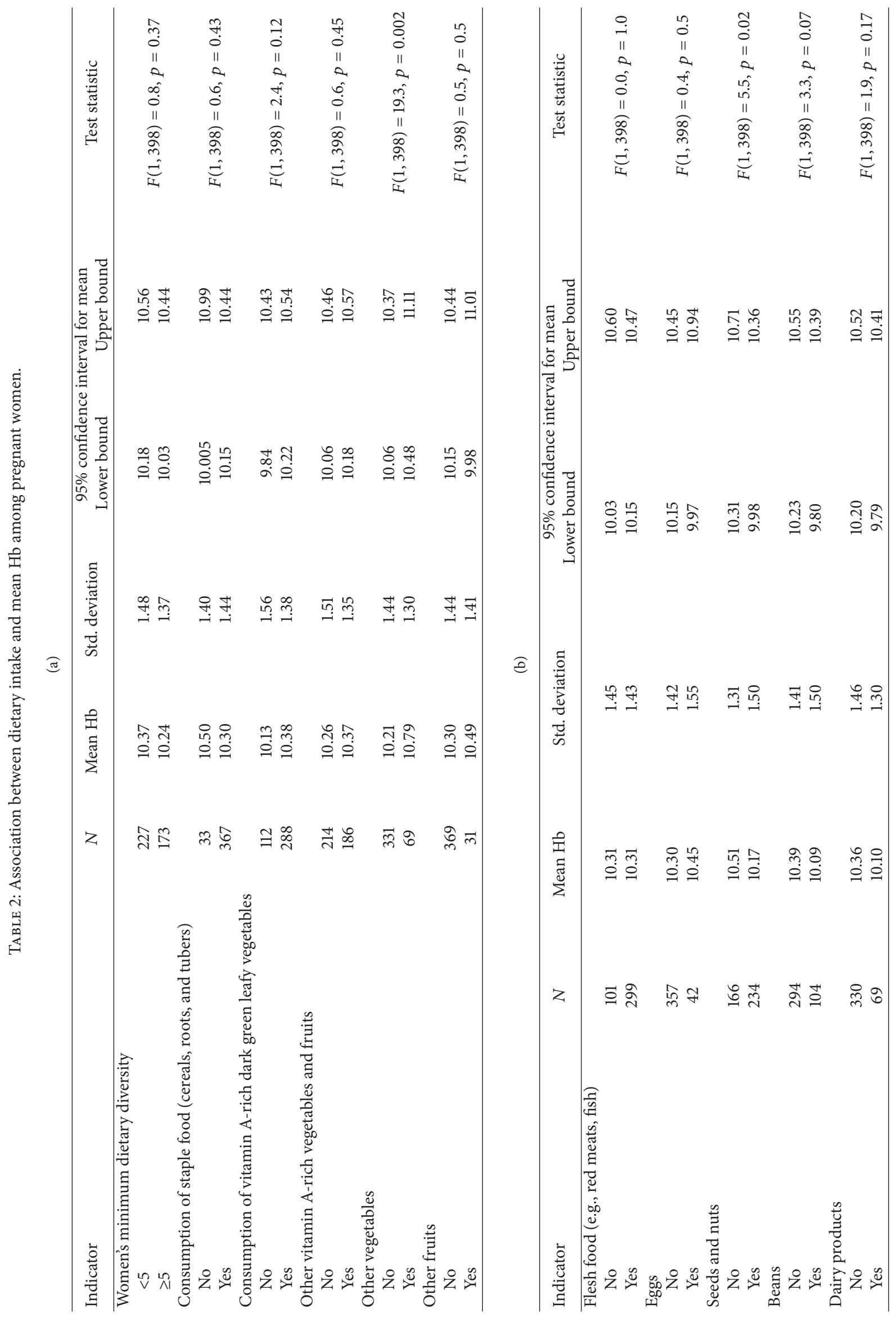


TABLE 3: Bivariate analyses of factors associated with anaemia of pregnant women $(n=400)$.

\begin{tabular}{|c|c|c|c|c|}
\hline \multirow[b]{2}{*}{ Characteristic } & \multicolumn{3}{|c|}{ Anaemia } & \multirow[b]{2}{*}{ Test statistic } \\
\hline & $N$ & $\begin{array}{c}\text { No } \\
n(\%)\end{array}$ & $\begin{array}{c}\text { Yes } \\
n(\%)\end{array}$ & \\
\hline \multicolumn{5}{|l|}{ Household wealth index } \\
\hline Low & 223 & $70(31.4)$ & $153(68.6)$ & \multirow{2}{*}{$\chi^{2}=5.2, p=0.02$} \\
\hline High & 177 & $75(42.4)$ & $102(57.6)$ & \\
\hline \multicolumn{5}{|l|}{ Midupper arm circumference } \\
\hline$<25 \mathrm{~cm}$ & 100 & $21(21.0)$ & $79(79.0)$ & \multirow{2}{*}{$\chi^{2}=10.2, p<0.001$} \\
\hline$\geq 25.0 \mathrm{~cm}$ & 297 & $122(41.1)$ & $175(58.9)$ & \\
\hline \multicolumn{5}{|l|}{ Educational level } \\
\hline None & 207 & $61(29.5)$ & $146(70.5)$ & \multirow{3}{*}{$\chi^{2}=13.1, p<0.006$} \\
\hline Low (primary and junior high) & 157 & $65(41.4)$ & $92(58.6)$ & \\
\hline High (at least senior high) & 36 & $19(52.8)$ & $17(47.2)$ & \\
\hline \multicolumn{5}{|l|}{ Gestational age } \\
\hline First trimester & 63 & $35(55.6)$ & $28(44.4)$ & \multirow{3}{*}{$\chi^{2}=12.0, p=0.002$} \\
\hline Second trimester & 143 & $48(33.6)$ & $95(66.4)$ & \\
\hline Third trimester & 193 & $62(32.1)$ & $131(67.9)$ & \\
\hline \multicolumn{5}{|l|}{ U-fives in household } \\
\hline None & 100 & $46(46.0)$ & $54(54.0)$ & \multirow{3}{*}{$\chi^{2}=7.9, p=0.02$} \\
\hline $1-2$ & 203 & $73(36.0)$ & $130(64.0)$ & \\
\hline At least 3 & 97 & $26(26.8)$ & $71(73.2)$ & \\
\hline \multicolumn{5}{|l|}{ Region of residence } \\
\hline Northern & 126 & $24(19.0)$ & $102(81.0)$ & \multirow{3}{*}{$\chi^{2}=31.1, p<0.001$} \\
\hline Upper East & 84 & $27(32.1)$ & $57(67.9)$ & \\
\hline Upper West & 190 & $94(49.5)$ & $96(50.5)$ & \\
\hline
\end{tabular}

TABLE 4: Determinants of haemoglobin concentration (g/dl) of pregnant women (multiple linear regression analysis).

\begin{tabular}{lccccc}
\hline Model & $\begin{array}{c}\text { Standardized } \\
\text { coefficients } \\
\text { Beta }\end{array}$ & Sig. & \multicolumn{2}{c}{$95.0 \%$ confidence interval for $(\beta)$} & \multicolumn{2}{c}{ Collinearity statistics } \\
\hline (Constant) & & 0.001 & Lower bound & Upper bound & Tolerance \\
Educational level & 0.122 & 0.013 & 0.06 & 8.12 & 0.48 \\
Frequency of ANC visits & 0.147 & 0.008 & 0.120 & 0.784 & 0.96 \\
Gestational age of woman & -0.172 & 0.002 & -0.55 & -0.12 & 0.75 \\
Under-five children in household & -0.117 & 0.017 & -0.37 & -0.04 & 0.74 \\
MUAC of mother & 0.216 & $<0.001$ & 0.05 & 0.12 & 0.95 \\
Height of mother & 0.141 & 0.006 & 0.006 & 0.04 & 0.87 \\
\hline
\end{tabular}

4.2. Dietary Diversity and Haematological Status. The results of this study showed that whilst controlling for potential confounding factors in multivariable analysis, haematological status of pregnant women was not associated with dietary diversity score (DDS) in rural settings. This finding collaborates that of a study carried out in Pakistan [30]. However, in an earlier study conducted in an urban setting of Northern Ghana, dietary diversity of pregnant women had positive effect on $\mathrm{Hb}$ in the third trimester [31]. In the present study, all pregnant women irrespective of the gestational age were included in the analysis.

The relationship between dietary diversity and anaemia remains inconclusive. Some other studies have reported a lack of association between dietary diversity and the prevalence of anaemia, especially in environments where many other factors other than diet exposure can increase the risk of getting anaemia $[32,33]$. It has also been reported that some pregnant women do restrict dietary intake in order to have 
smaller babies and therefore easier deliveries [34, 35]. In Ethiopia, women with restrictive dietary habits were reported to have $39 \%$ higher risk of anaemia compared to those without restrictive dietary behaviour [36] where maternal dietary diversity was protective of pregnancy anaemia [3739].

Dietary diversity is considered to be a key indicator for assessing the access, utilization, and quality of diet of individuals or household [40]. Though high quality diet can protect against anaemia, some eating patterns or habits may predispose individuals to a higher risk for developing anaemia. For example, high fibre diets can inhibit the absorption of iron; low fat diets can equally inhibit iron absorption since fat is needed for iron absorption, high tea, and coffee consumption but without vitamin $\mathrm{C}$ intake it also inhibits iron absorption. Individual dietary diversity scores have been shown to indicate adequate nutrient intake and it can be used as a proxy indicator for measuring nutrient adequacy among pregnant females [41].

This notwithstanding women's dietary behaviours and intake during pregnancy are strongly influenced by different cultural practices, myths, and taboos $[42,43]$.

The aetiology of anaemia in pregnancy does not seem to be the same in every geographical area and season. Whereas, in Malawi, iron deficiency was an important contributor to anaemia in pregnancy, Saaka et al. [44] reported that iron deficiency did not appear to be a major risk factor for anaemia among pregnant women in the Agogo district of Ghana. Additionally, diet is only one of the protective factors against anaemia and dietary diversity may not be the most pressing constraint. The apparent lack of association in the present study may also be due to the fact that there was very little variation with respect to dietary diversity among the study participants.

4.3. ANC Attendance and Anaemia. Our results showed that prevalence of anaemia among women who attended antenatal care at least four times was significantly lower and they were less likely of becoming anaemic. The positive contribution of early initiation of ANC attendance to haematological status is probably due to the benefits associated with ANC. For example, women who seek ANC frequently are more likely to benefit from prophylactic measures against malarial infection, iron, and folic acid supplementation and that of nutrition and health education. The finding supports previous studies which have reported an association between infrequent prenatal consultations and the presence of anaemia [45-48]. Similarly, the number of antenatal care visits was a strong predictor of anaemia among pregnant women in Westmoreland, Jamaica [48].

There is an increased foetal demand for haematopoietic factors as pregnancy progresses $[49,50]$ and so women who will not avail themselves to health services early enough may suffer the consequences of increased demand for nutrients. Such women are also more unlikely to take advantage of accessing health services to treat any underlying maternal diseases and untreated anaemia in early pregnancy that are likely to worsen in the course of pregnancy. In this study sample, less than $16 \%$ reported for ANC in their first trimester and so many of the women did not present for antenatal care until being late in the second trimester of pregnancy. Pregnant women in the study area should be educated to report early for ANC.

Though iron supplementation is key intervention for pregnant women in the study area, late and infrequent ANC attendance will deny these women the benefits of such an intervention. Also, nonadherence to the recommended iron supplementation could adversely affect their iron status but our study did not assess this factor.

4.4. Anaemia and Maternal Education. Low maternal educational level significantly predicted anaemia in this study. Women who had higher education level were less likely to be anaemic, perhaps because better educated mothers were more likely to adopt healthier feeding habits $[19,30]$. This could also be explained partly by the fact that women with lower educational level may find it difficult securing better jobs and therefore have less economic power. Education may also enable women to make independent decisions that allow them to have greater access to household resources that are important to nutritional status [51]. Our results further give support to the call to invest in girl child education as a way to promoting the general wellbeing of future mothers $[48,52]$.

4.5. Maternal Height and Risk of Anaemia. In adjusted models, a $1 \mathrm{~cm}$ increase in maternal height was associated with a decreased risk of anaemia. This means maternal height and haemoglobin concentrations were directly associated. This association has been reported in earlier studies [53]. Adult height reflects a mother's health status that has been acquired through various life experiences including the social and environmental exposures [54].

4.6. Household Size and Risk of Anaemia. In this study sample, there was an inverse relationship between the prevalence of maternal anaemia and the number of under-five children in the household. This is consistent with the findings of similar studies conducted in Kuwait where anaemia was positively associated with birth order and in Amazonia where high maternal parity is positively associated with anaemia $[55,56]$. This relationship may be explained by the fact that a woman who gives frequent birth is more likely to deplete her iron stores.

4.7. Maternal Nutritional Status and Anaemia. Multivariable regression analysis showed that pregnant women of higher midupper arm circumference (MUAC) $\geq 25.0 \mathrm{~cm}$ had significantly higher haemoglobin concentrations. A study in rural northern Tanzania had earlier reported that an arm circumference less than $25 \mathrm{~cm}$ was associated with anaemia [57]. Though MUAC is unaffected by gestational age [19], prolonged infections can adversely affect the size of it as a result of their consequences leading to both anaemia and wasting and therefore an apparent association between the arm circumference and anaemia [57].

4.8. Limitation of the Study. Dietary diversity was assessed based on responses obtained from participants (e.g., dietary 
recall) during the pregnancy and this depended on memory and their ability to recall accurately. Recall bias could not be ruled out completely. The 24-hour dietary recall may not truly represent the usual intake. However, methods used in assessing dietary diversity are useful for ranking individuals but do not necessarily permit exact assessments of absolute nutrient intake.

The study also relied partly on secondary data about participants recorded by health professionals during the pregnancy. Therefore, any error in measurements, readings, or recordings of these parameters and indices will be reflected in the results. However, with the level of professionalism of health workers in the institutions involved in the study, this is expected to be minimal. The cross-sectional study design used to collect data also makes it difficult to demonstrate cause-and-effect relationships.

It is also worth mentioning that it was not possible to obtain haematimetric and biochemical indicators necessary for the diagnosis and estimation of the magnitude of iron deficiency by virtue of the available haematological evaluation technique that was used in the study.

\section{Conclusions}

Whilst controlling for potential confounding factors in multivariable analysis, haematological status of pregnant women was not associated with maternal dietary diversity score (DDS) irrespective of the socioeconomic status. The study findings suggest that anaemia was higher with increased gestational age and lower educational level. This implies the need to target interventions to these vulnerable groups of women. Furthermore, making early and timely visits to the antenatal clinic would help to lower the prevalence of anaemia among pregnant women in Northern Ghana.

\section{Competing Interests}

The authors declare that they have no competing interests.

\section{Authors' Contributions}

Mahama Saaka conceived the study, participated in its design, and did the analysis and interpretation of data. Jeremiah Oladele assisted with the development of the questionnaire and data collection from the field. Asamoah Larbi and Irmgard Hoeschle-Zeledon assisted in data collection and manuscript writing and critically commented on the draft manuscript. All authors gave final approval of the version to be published.

\section{Acknowledgments}

The authors would like to gratefully acknowledge funding received from IITA Africa RISING Project under the USAID Feed the Future Nutrition. We are thankful to the data collection team members for their hard work and commitment. The data could not have been obtained without the cooperation and support of the programme communities, especially the mothers and caregivers who took time off from their busy schedules to respond to the interviewers. Their involvement and cooperation are highly appreciated.

\section{References}

[1] A. Kumar, A. K. Rai, S. Basu, D. Dash, and J. S. Singh, "Cord blood and breast milk iron status in maternal anemia," Pediatrics, vol. 121, no. 3, pp. e673-e677, 2008.

[2] M. F. Picciano, "Pregnancy and lactation: physiological adjustments, nutritional requirements and the role of dietary supplements," Journal of Nutrition, vol. 133, no. 6, pp. 1997S-2002S, 2003.

[3] R. A. El-Farrash, E. Abdel Rahman Ismail, and A. Shafik Nada, "Cord blood iron profile and breast milk micronutrients in maternal iron deficiency anemia," Pediatric Blood \& Cancer, vol. 58, no. 2, pp. 233-238, 2012.

[4] U. Zangmo, M. de Onis, and T. Dorji, “The nutritional status of children in Bhutan: results from the 2008 National Nutrition Survey and trends over time," BMC Pediatrics, vol. 12, article 151, 2012.

[5] T. O. Scholl, "Iron status during pregnancy: setting the stage for mother and infant," The American Journal of Clinical Nutrition, vol. 81, no. 5, pp. 1218S-1222S, 2005.

[6] F. Branca, L. Mahy, and T. S. Mustafa, "The lack of progress in reducing anaemia among women: the inconvenient truth," Bulletin of the World Health Organization, vol. 92, no. 4, p. 231, 2014.

[7] E. Kavosi, Z. Hassanzadeh Rostami, A. Nasihatkon, M. Moghadami, and M. Heidari, "Prevalence and determinants of under-nutrition among children under six: a cross-sectional survey in fars province, Iran," International Journal of Health Policy and Management, vol. 3, no. 2, pp. 71-76, 2014.

[8] D. K. Kinyoki, J. A. Berkley, G. M. Moloney, N.-B. Kandala, and A. M. Noor, "Predictors of the risk of malnutrition among children under the age of 5 years in Somalia," Public Health Nutrition, vol. 18, no. 17, pp. 3125-3133, 2015.

[9] P. T. Muniz, T. G. de Castro, T. S. de Araújo et al., "Child health and nutrition in the Western Brazilian Amazon: populationbased surveys in two counties in Acre State," Cadernos de Saúde Pública, vol. 23, no. 6, pp. 1283-1293, 2007.

[10] R. K. Singh and S. Patra, "Extent of anaemia among preschool children in EAG States, India: a challenge to policy makers," Anemia, vol. 2014, Article ID 868752, 9 pages, 2014.

[11] R. E. Black, L. H. Allen, Z. A. Bhutta et al., "Maternal and child undernutrition: global and regional exposures and health consequences," The Lancet, vol. 371, no. 9608, pp. 243-260, 2008.

[12] M. Hoque and M. E. Hoque, "Knowledge of danger signs for major obstetric complications among pregnant KwaZulu-Natal women: implications for health education," Asia-Pacific Journal of Public Health, vol. 23, no. 6, pp. 946-956, 2011.

[13] S. Ziaei, E. Hatefnia, and G. Togeh, "Iron status in newborns born to iron-deficient mothers," Iranian Journal of Medical Sciences, vol. 28, no. 2, pp. 62-64, 2003.

[14] Y. Neggers and R. L. Goldenberg, "Some thoughts on body mass index, micronutrient intakes and pregnancy outcome," Journal of Nutrition, vol. 133, no. 5, supplement 2, pp. 1737S-1740S, 2003.

[15] K. Abu-Saad and D. Fraser, "Maternal nutrition and birth outcomes," Epidemiologic Reviews, vol. 32, no. 1, pp. 5-25, 2010.

[16] GSS, Ghana Living Standards Survey, Ghana Statistical Service (GSS), Accra, Ghana, 2014. 
[17] B. L. Horta, R. V. Santos, J. R. Welch et al., "Nutritional status of indigenous children: findings from the First National Survey of Indigenous People's Health and Nutrition in Brazil," International Journal for Equity in Health, vol. 12, article 23, 2013.

[18] FAO and FHI, Minimum Dietary Diversity for Women: A Guide for Measurement, FAO, Rome, Italy, 2016.

[19] K. Krasovec and M. Anderson, Eds., Maternal Nutrition and Pregnancy Outcomes: Anthropometric Assessment, Pan American Health Organization (PAHO), Washington, DC, USA, 1991.

[20] A. M. Tang, M. Chung, K. Dong et al., Determining a Global Mid-Upper Arm Circumference Cutoff to Assess Malnutrition in Pregnant Women, FHI 360/Food and Nutrition Technical Assistance III Project (FANTA), Washington, DC, USA, 2016.

[21] B. D. Benoist, E. McLean, I. Egll, and M. Cogswell, Worldwide Prevalence of Anaemia 1993-2005: WHO Global Database on Anaemia, WHO, Geneva, Switzerland, 2008.

[22] WHO, Worldwide Prevalence of Anemia 1993-2005: WHO Global Database of Anaemia, World Health Organization, Geneva, Switzerland, 2008.

[23] S. Vyas and L. Kumaranayake, "Constructing socio-economic status indices: how to use principal components analysis," Health Policy and Planning, vol. 21, no. 6, pp. 459-468, 2006.

[24] D. Filmer and L. H. Pritchett, "Estimating wealth effects without expenditure data-or tears: an application to educational enrollments in states of India," Demography, vol. 38, no. 1, pp. 115-132, 2001.

[25] S. O. Rutstein and K. Johnson, DHS Comparative Reports 6: The DHS Wealth Index, ORC Macro, MEASURE DHS, Calverton, Md, USA, 2004.

[26] L. D. Howe, J. R. Hargreaves, and S. R. A. Huttly, "Issues in the construction of wealth indices for the measurement of socioeconomic position in low-income countries," Emerging Themes in Epidemiology, vol. 5, article 3, 2008.

[27] D. J. VanderJagt, H. S. Brock, G. S. Melah, A. U. El-Nafaty, M. J. Crossey, and R. H. Glew, "Nutritional factors associated with anaemia in pregnant women in northern Nigeria," Journal of Health, Population and Nutrition, vol. 25, no. 1, pp. 75-81, 2007.

[28] E. McLean, M. Cogswell, I. Egli, D. Wojdyla, and B. De Benoist, "Worldwide prevalence of anaemia, WHO Vitamin and Mineral Nutrition Information System, 1993-2005," Public Health Nutrition, vol. 12, no. 4, pp. 444-454, 2009.

[29] Ghana Statistical Service (GSS), Ghana Health Service (GHS), and ICF International, Ghana Demographic and Health Survey, GSS, GHS, and ICF International, Rockville, Md, USA, 2014.

[30] F. Ali, I. Thaver, and S. A. L. Khan, "Assessment of dietary diversity and nutritional status of pregnant women in Islamabad, Pakistan," Journal of Ayub Medical College, Abbottabad, vol. 26, no. 4, pp. 506-509, 2014.

[31] M. Saaka and A. Abdul Rauf, "Role of dietary diversity in ensuring adequate haematological status during pregnancy," International Journal of Medical Research \& Health Sciences, vol. 4, no. 4, pp. 749-755, 2015.

[32] C. Kubuga, K. Lee, S. Song, and W. O. Song, "The association between dietary diversity score and iron deficiency anemia among reproductive-aged women in Ghana," The FASEB Journal, vol. 30, no. 1, supplement, p. 899.11, 2016.

[33] C. M. McDonald, J. McLean, H. Kroeun, A. Talukder, L. D. Lynd, and T. J. Green, "Household food insecurity and dietary diversity as correlates of maternal and child undernutrition in rural Cambodia," European Journal of Clinical Nutrition, vol. 69, no. 2, pp. 242-246, 2015.
[34] M. Saaka and S. Mutaru, Integrating Agricultural and Nutritional Interventions for Improved Nutritional Status of Rural Families in Northern Ghana: Baseline Survey Report, International Institute of Tropical Agriculture (IITA), Ibadan, Nigeria, 2013.

[35] C. A. Gewa and T. F. Leslie, "Distribution and determinants of young child feeding practices in the East African region: demographic health survey data analysis from 2008-2011," Journal of Health, Population and Nutrition, vol. 34, no. 1, article no. 6, 2015.

[36] H. Kedir, Y. Berhane, and A. Worku, "Khat chewing and restrictive dietary behaviors are associated with anemia among pregnant women in high prevalence rural communities in eastern Ethiopia," PLoS ONE, vol. 8, no. 11, Article ID e78601, 2013.

[37] H. K. Biesalski, "Meat and cancer: meat as a component of a healthy diet," European Journal of Clinical Nutrition, vol. 56, pp. S2-S11, 2002.

[38] F. B. Hu and W. C. Willett, The Relationship between Consumption of Animal Products (Beef, Pork, Poultry, Eggs, Fish and Dairy Products) and Risk of Chronic Diseases: A Critical Review, Harvard School of Public Health, Boston, Mass, USA, 1998.

[39] T. A. Zerfu, M. Umeta, and K. Baye, "Dietary diversity during pregnancy is associated with reduced risk of maternal anemia, preterm delivery, and low birth weight in a prospective cohort study in rural Ethiopia," American Journal of Clinical Nutrition, vol. 103, no. 6, pp. 1482-1488, 2016.

[40] FAO, Guidelines for Measuring Household and Individual Dietary Diversity, Food and Agriculture Organization of the United Nations, Rome, Italy, 2011.

[41] L. M. Wen, V. M. Flood, J. M. Simpson, C. Rissel, and L. A. Baur, "Dietary behaviours during pregnancy: findings from first-time mothers in southwest Sydney, Australia," International Journal of Behavioral Nutrition and Physical Activity, vol. 7, article 13, pp. $1-7,2010$.

[42] R. Patil, A. Mittal, D. Vedapriya, M. I. Khan, and M. Raghavia, "Taboos and misconceptions about food during pregnancy among rural population of Pondicherry," Calicut Medical Journal, vol. 8, no. 2, article e4, 2010.

[43] G. Meena, "Associations Between maternal nutritional characteristics and the anthropometric indices of their full-term and pre-term newborns," Pakistan Journal of Nutrition, vol. 4, no. 11, pp. 343-349, 2012.

[44] M. Saaka, A. Larbi, I. Hoeschle-Zeledon, and B. Appiah, Child Malnutrition in Northern Ghana: Evidence, Factors and Recommendations from a New Study, Centre for Science and Health Communication, Ghana International Institute of Tropical Agriculture, University for Development Studies, Lagos, Nigeria, 2015.

[45] S. Chang, W. He, F. Jia, and C. Chen, "Analysis on the changes of nutritional status in China anemia status of children under 5 in China," Wei Sheng Yan Jiu, vol. 36, no. 2, pp. 210-212, 2007.

[46] L. G. de Souza, R. V. Santos, H. Pagliaro, M. S. Carvalho, N. M. Flowers, and C. E. A. Coimbra Jr., "Demography and health of the Xavante Indians of Central Brazil," Cadernos de Saude Publica, vol. 27, no. 10, pp. 1891-1905, 2011.

[47] K. McSweeney and S. A. Arps, "A 'demographic turnaround': the rapid growth of indigenous populations in lowland South America," Latin American Research Review, vol. 40, no. 1, pp. 3-29, 2005. 
[48] A. M. Charles, D. Campbell-Stennett, N. Yatich, and P. E. Jolly, "Predictors of anemia among pregnant women in Westmoreland, Jamaica," Health Care for Women International, vol. 31, no. 7, pp. 585-598, 2010.

[49] T. H. Bothwell, R. W. Charlton, J. D. Cook, and C. A. Finch, Eds., Iron Metabolism in Man, Blackwell Scientific Publications, Oxford, UK, 1979.

[50] N. K. M. de Leeuw, L. Lowenstein, and Y.-S. Hsieh, "Iron deficiency and hydremia in normal pregnancy," Medicine, vol. 45, no. 4, pp. 291-315, 1966.

[51] ACC/SCN, Women and Nutrition. Administration Committee on Coordination-Sub-Committee on Nutrition, 1990.

[52] S. Villalpando, T. Shamah-Levy, C. I. Ramírez-Silva, F. MejíaRodríguez, and J. A. Rivera, "Prevalence of anemia in children 1 to 12 years of age. Results from a nationwide probabilistic survey in Mexico," Salud Publica de Mexico, vol. 45, supplement 4, pp. S490-S498, 2003.

[53] S. V. Subramanian, L. K. Ackerson, G. D. Smith, and N. A. John, "Association of maternal height with child mortality, anthropometric failure, and anemia in India," The Journal of the American Medical Association, vol. 301, no. 16, pp. 1691-1701, 2009.

[54] K. Silventoinen, "Determinants of variation in adult body height," Journal of Biosocial Science, vol. 35, no. 2, pp. 263-285, 2003.

[55] E. K. Amine and F. A. Al-Awadi, "Nutritional status survey of preschool children in Kuwait," Eastern Mediterranean Health Journal, vol. 2, no. 3, pp. 386-395, 1996.

[56] M. A. Cardoso, K. K. G. Scopel, P. T. Muniz, E. Villamor, and M. U. Ferreira, "Underlying factors associated with anemia in Amazonian children: a population-based, cross-sectional study," PLoS ONE, vol. 7, no. 5, Article ID e36341, 2012.

[57] S. G. Hinderaker, B. E. Olsen, R. T. Lie et al., "Anemia in pregnancy in rural Tanzania: associations with micronutrients status and infections," European Journal of Clinical Nutrition, vol. 56, no. 3, pp. 192-199, 2002. 


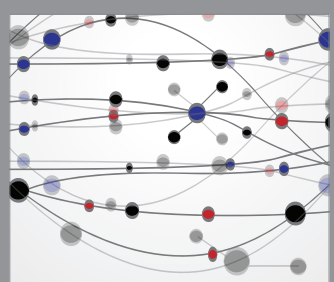

The Scientific World Journal
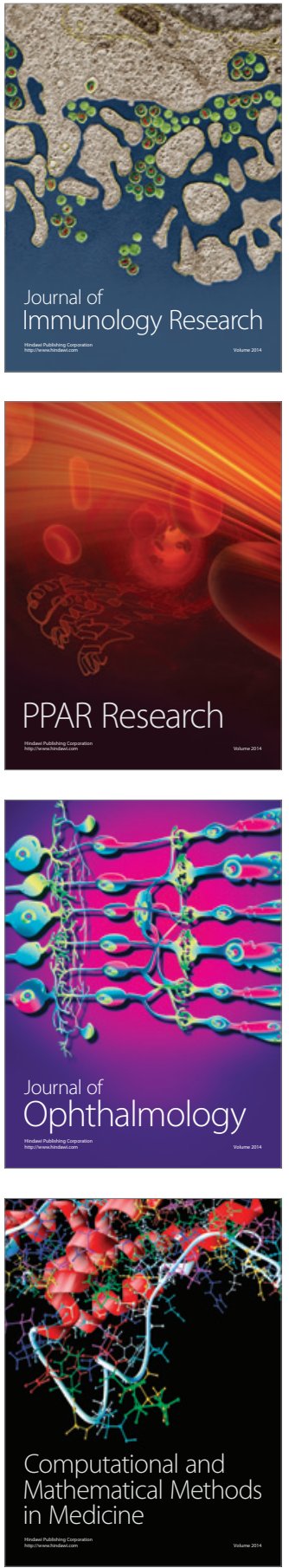

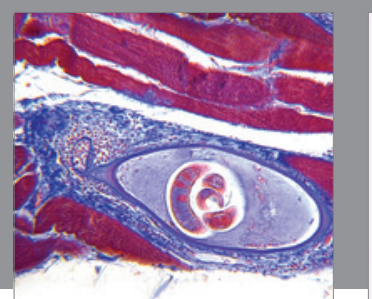

Gastroenterology Research and Practice
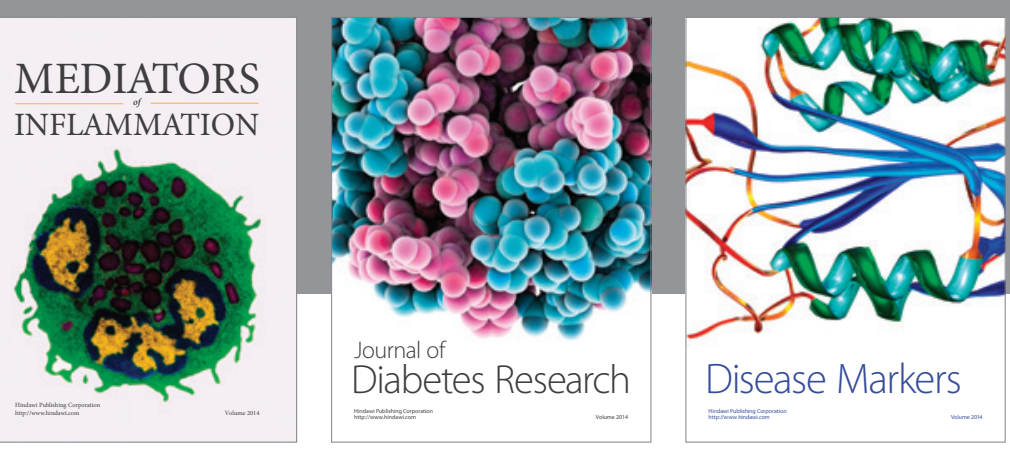

Disease Markers

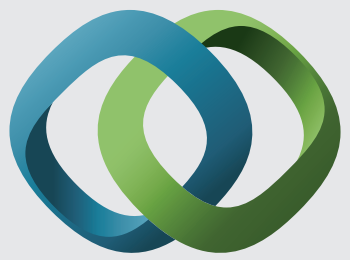

\section{Hindawi}

Submit your manuscripts at

https://www.hindawi.com
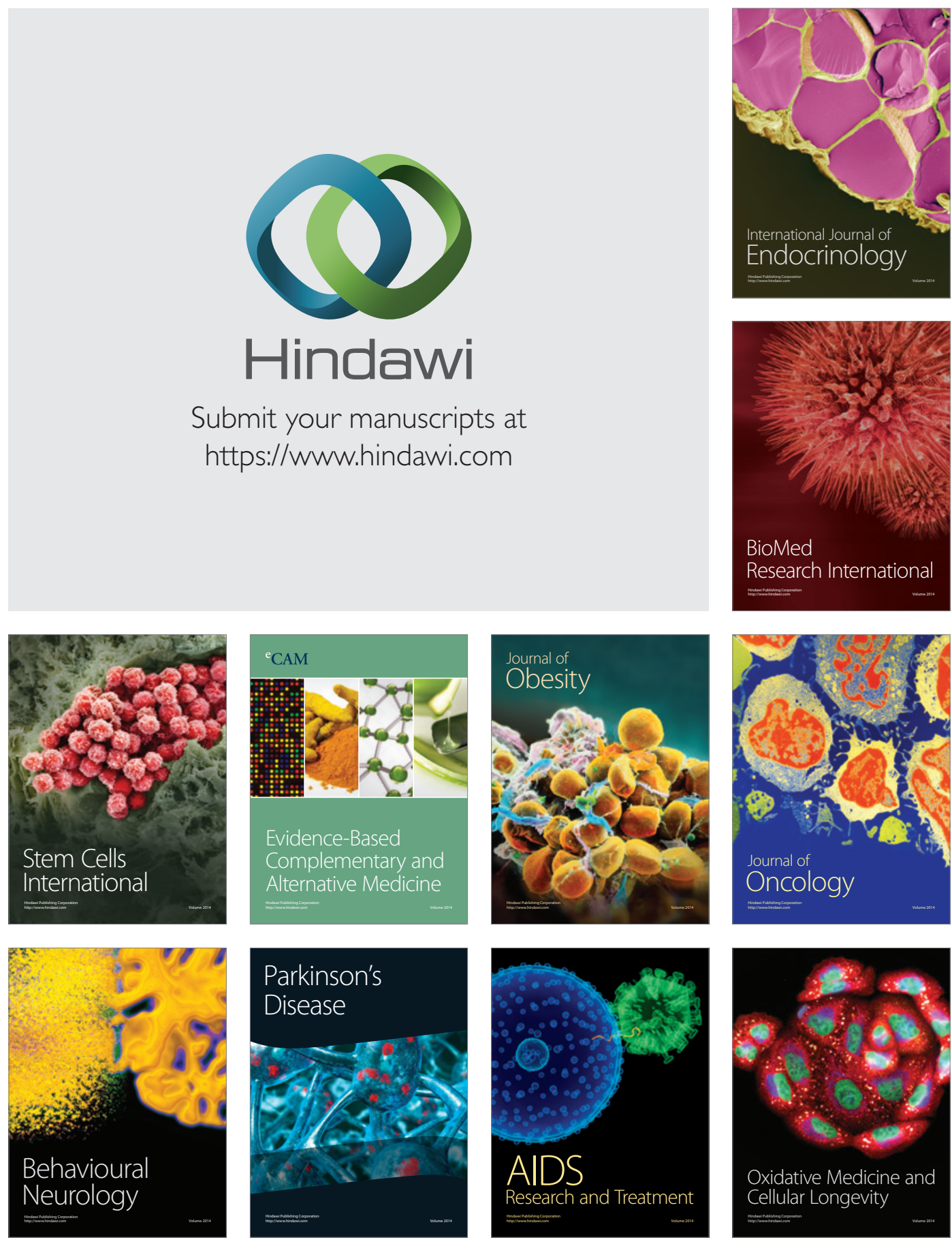